\section{Misconduct in research}

\section{Misconduct is not reported in biomedical journals in France}

EDrroR,-I was disappointed that Richard Smith was unable to list France among the countries having a system for tackling misconduct in research. ${ }^{1}$ It seems that misconduct occurs in northern Europe and avoids the Latin culture; is there an explanation? France is known for the quality of its research and should be one of the leading countries in all domains of science, including integrity.

Smith should not complain that Britain fails to respond to evidence of misconduct when compared with the rest of the world. Disclosure of information to peers and to the public through the lay press, as happens in Britain, does not occur in most countries. Only six countries have set up a commission on integrity, and in southern Europe it will probably take a generation to change people's attitudes.

Misconduct does exist in France but is not reported in biomedical journals. The publication process is more a way of promoting people than of disseminating science. The policy of retracting papers seems odd to French scientists (if they understand it). The quality of papers is not a concern for many scientists. In their chapter in the book Fraud and Misconduct in Medical Research Husson et al do not describe any particular cases in France. ${ }^{2}$ They state, however, that "most countries maintain a sort of "black list' of persons guilty of fraud but their identities are only partly known to the persons responsible for clinical trials: health authorities, sponsors, and investigators." These blacklists are not disclosed, and names are put on them on the basis of suspicions rather than on the basis of evidence obtained during in depth investigations. A colleague and I have described some cases that we know of, but we did not give the names of the investigators or institutions. ${ }^{3}$ I have never known a French medical journal to report the evidence in a case of misconduct.

A new development is a recent unofficial report by the central unit for the prevention of corruption, which states that corruption (not scientific fraud) exists in the health sector in France. This report was quoted on the front page of Quotidien du Médecin. ${ }^{4}$ It might well be that scientists who have been corrupted financially also commit misconduct in research. The lay press is beginning to tackle the problem-for example, the news magazine L'Express, which has a wide circulation, cited three German cases. ${ }^{5}$ The article states that such misconduct is rare in France as most researchers are public employees. I suggest that Smith submits an editorial to $\mathbf{L a}$ Presse Médicale entitled "La France devrait déjà publier les listes noires de fraudeurs" ("France should publish the blacklist of those who have committed fraud").

\section{de l'évaluation Médicale,
159 rue Nationale,}

75013 Paris,

France

1 Smith R. Time to face up to research misconduct. $B M f$ 1996;312:789-90. (30 March.)
2 Husson JM, Bogaievsky Y, Hvidberg E, Schwarz J, Chada D. Fraud in clinical research on medicines in the European union: facts and proposals. In: Lock S, Wells F, eds. Fraud and misconduct in medical research. London: BMJ Publishing, 1996:206-25.

3 Lagarde $D$, Maisonneuve $H$. Fraud in clinical research from the original idea to publication: the French scene. In: Lock
$\mathrm{S}$, Wells $\mathrm{F}$, eds. Fraud and misconduct in medical research. S, Wells F, eds. Fraud and misconduct

4 Santé: le risque de la corruption. Quotidien du Médecin 1996 Apr 5.

5 Quand les chercheurs trichent. L'Express 1996 Apr 18.

\section{Profession must police itself}

EDrToR,-The role of medical research in society depends on public trust, which in turn relies on the view that science is incorruptible. Members of the profession may face a dilemma when they discover fraud. Do they risk loss of public confidence by exposing other members of the profession, possibly friends or colleagues, who fall short of the standards expected or do they become accomplices by failing to expose the fraud? The latter course of action may prove more damaging to public confidence in the long term if we draw parallels from other institutions that also depend on public trust. The criminal justice system has been discredited by disclosures that those at the highest levels permitted miscarriages of justice rather than admit that there are flaws in the system. Confidence in churches and social services was tarnished when it was disclosed that those in authority helped to conceal the sexual abuse of children. The attempts of those in authority to hide wrongdoing has damaged these institutions far more than would have been the case if errors had been admitted and the guilty had been dealt with quickly.

Fraud and other forms of dishonesty in medical research are clearly much more common than is generally realised. Even when individuals are exposed, correction of the record is slow and incomplete. Journals are often unwilling to retract dishonest papers, perhaps fearing guilt by association or charges of incompetent refereeing. It is clear to many who are interested in scientific fraud that the time left for self regulation is rapidly running out. ${ }^{1}$ Fraud is now so prevalent and so well tolerated that the profession must act swiftly to police itself if it wishes to avoid the imposition of external controls. Those outside the profession should be asking, "Why should we trust medical scientists to regulate themselves when history has shown their past failures?"

Royal Shrewsbury Hospital,

PETER WILMSHURST

Shrewsbury SY3 8XQ

1 Smith R. Time to face up to research misconduct. $B M \varsubsetneqq$ 1996;312:789-90. (30 March.)

\section{Medical Research Council is setting up} rigorous procedures

EDrToR,-Recent editorials in the Lancet and the $B M F$ draw attention to the issue of misconduct in scientific research. ${ }^{12}$ They argue that Britain lacks the structures and processes needed to mount an effective response.

The detection of scientific misconduct is a high priority for the Medical Research Council. We are concerned with its exposure, its appropriate handling, and the education of researchers in good research practices. We are not in favour of a national policing body, but as a responsible employer we are currently concluding internal negotiations and expect to be in a position to implement our own rigorous procedures within the next couple of months. These will provide for the protection of people who make allegations as well as independent investigation of alleged misconduct. We are also working on a comprehensive set of guidance notes for our researchers.

NICK WINTERTON

Medical Research Council, London WIN 4AL

1 Dealing with deception [editorial]. Lancet 1996;347:843. 2 Smith R. Time to face up to research misconduct. $B M \mathscr{f}^{\prime}$ 1996;312:789-80. (30 March.)

\section{Double reading of screening mammograms will have resource implications}

EDrToR,--Jackie Brown and colleagues show that in their breast screening unit double reading of screening mammograms with recall by consensus between film readers is cost effective. ${ }^{1}$ Unfortunately, these results cannot be directly extrapolated to the NHS breast screening programme as the study was carried out during the first (prevalence) screening round, when the overall rate of detection of cancer is higher and the number of additional cancers detected by double reading is likely to be greater than in subsequent rounds. It is also impossible to quantify the likely benefit in terms of a reduction in

\section{Advice to authors}

We receive more letters than we can publish: we can currently accept only about one third. We prefer short letters that relate to articles published within the past four weeks. Letters received after this deadline stand less chance of acceptance. We also publish some "out of the blue" letters, which usually relate to matters of public policy.

When deciding which letters to publish we favour originality, assertions supported by data or by citation, and a clear prose style. $W$ it, passion, and personal experience also have their place.

Letters should have fewer than $\mathbf{4 0 0}$ words (please give a word count) and no more than five references (including one to the $B M F$ article to which they relate); references should be in the Vancouver style. We welcome pictures.

Letters should be typed and signed by each author, and each author's current appointment and address should be stated. We encourage you to declare any conflict of interest.

Please enclose a stamped addressed envelope if you would like to know whether your letter has been accepted or rejected.

Letters will be edited and may be shortened. 